\title{
Fabrication of PCD Skiving Cutter by UV Nanosecond Laser
}

\author{
Jianlei Cui ${ }^{1,2, *} \mathbb{C}$, Xuyang Fang ${ }^{1}$, Xiangyang Dong ${ }^{1}$, Xuesong Mei ${ }^{1, *} \mathbb{C}$, Kaida Xu ${ }^{3} \mathbb{C}$, Zhengjie Fan ${ }^{1,2} \mathbb{C}^{1}$, \\ Zheng Sun ${ }^{1}$ and Wenjun Wang ${ }^{1}$
}

1 State Key Laboratory for Manufacturing Systems Engineering, Xi'an Jiaotong University, Xi'an 710049, China; fxy1997@stu.xjtu.edu.cn (X.F.); lovelyhat@stu.xjtu.edu.cn (X.D.); fanzhengjie@xjtu.edu.cn (Z.F.); zheng.sun@xjtu.edu.cn (Z.S.); wenjunwang@mail.xjtu.edu.cn (W.W.)

2 Department of Project, Xi'an Jiaotong University Shenzhen Research Institute, Shenzhen 518057, China

3 School of Information and Communications Engineering, Xi'an Jiaotong University, Xi'an 710049, China; kaidaxu@xjtu.edu.cn

* Correspondence: cjlxjtu@mail.xjtu.edu.cn (J.C.); xsmei@mail.xjtu.edu.cn (X.M.)

check for updates

Citation: Cui, J.; Fang, X.; Dong, X.; Mei, X.; Xu, K.; Fan, Z.; Sun, Z.; Wang, W. Fabrication of PCD Skiving Cutter by UV Nanosecond Laser. Materials 2021, 14, 4027. https://doi.org/ $10.3390 / \mathrm{ma} 14144027$

Academic Editors: Mingjun Chen, Jian Cheng, Qi Liu and Xichun Luo

Received: 7 June 2021

Accepted: 14 July 2021

Published: 19 July 2021

Publisher's Note: MDPI stays neutral with regard to jurisdictional claims in published maps and institutional affiliations.

Copyright: (c) 2021 by the authors. Licensee MDPI, Basel, Switzerland. This article is an open access article distributed under the terms and conditions of the Creative Commons Attribution (CC BY) license (https:/ / creativecommons.org/licenses/by/ $4.0 /)$.

\begin{abstract}
Polycrystalline diamond (PCD) skiving cutter has dominated research in recent years. However, the traditional methods of fabrication have failed to cut the diamond with high quality. We propose the two-step laser machining process combining roughing machining with orthogonal irradiation and finishing machining with tangential irradiation. In addition, the processing effect and mechanism of different lasers on the diamond were investigated by a finite element analysis. It's proved that the ultraviolet nanosecond laser is an excellent machining method for the processing of diamond. Furthermore, the effect of the processing parameters on the contour accuracy $\left(R_{\mathrm{t}}\right)$ was studied. The result indicates that the $R_{\mathrm{t}}$ value decreases first and then increases as the increase of the line interval, scanning speed and defocusing amount (no matter positive or negative defocus). Further, Raman spectroscopy was applied to characterize the diamond surface under different cutting methods and the flank face of the tool after processing. Finally, a high-quality PCD skiving cutter was obtained with an $R_{\mathrm{t}}$ of $5.6 \mu \mathrm{m}$ and no phase transition damage.
\end{abstract}

Keywords: PCD skiving cutter; UV nanosecond laser; contour accuracy; surface morphology

\section{Introduction}

The demand of shape accuracy, surface quality, working stability and reliability is increasing incessantly in miniature parts with the development of aerospace, electronics, ultra-precision machinery and other fields [1-5]. The gear is a significant mechanical component that transmits power and movement. The main manufacturing methods for gear include gear hobbing, milling, shaper, broaching, skiving, etc. The skiving method is receiving more and more attention due to its higher efficiency and accuracy. The fabrication of a skiving cutter is the key to obtain a high precision gear.

Polycrystalline diamond (PCD) has the advantages of extremely high hardness (only inferior to single-crystal diamond), high strength, wear resistance and can be sharpened to an extremely sharp blade. The PCD has become one of the most suitable materials for diamond cutting tools. Due to its ultra-high hardness, the traditional cutting methods are unideal to process diamond. However, laser has obvious advantages in processing the diamond due to its excellent properties such as high peak power, machining accuracy and efficiency, non-contact processing, wide processing range [6-9].

Discussions with respect to the laser processing of the diamond have dominated research in recent years. Butler-Smith et al. [10] reported there is a $2 \mu \mathrm{m}$ thick graphite layer on the diamond surface after processing with a $10 \mathrm{~ns}$ laser, and it has an abrupt boundary with the diamond structure. Harrison et al. [11] used a $200 \mathrm{~ns}$ and $1064 \mathrm{~nm}$ laser to cut polycrystalline diamond composites, and studied the ablation characteristics, the removal rate of nanosecond laser processing PCD. Everson et al. [12] studied the effect of the repetition frequency and feed rate on PCD slit and surface morphology with a 
nanosecond laser. According to Konrad et al. [13], a cutting edge with a corner radius of $3 \mu \mathrm{m}$ and a tolerance within $2 \mu \mathrm{m}$ on a polycrystalline diamond was obtained used a $10 \mathrm{ps}$ laser. Dold et al. [14] compared the diamond cutting tools processed by picosecond laser with the diamond cutting tools processed by traditional methods. The results indicate that the surface of cutting tools processed by laser processing is smoother. This paper aims to study the fabrication process of PCD skiving cutter by UV nanosecond laser, analyze the difference between different lasers by finite element simulation and Raman detection was carried out to analyze the phase transition of the cutting surface.

\section{Materials and Methods}

A PCD diamond blank with a diameter of $20 \mathrm{~mm}$ and a thickness of $2 \mathrm{~mm}$ was used as the skiving cutter material sample. In the experiment, the parameters of the incident UV nanosecond laser (INNO-FOTIA-355-OEM-2, Shenzhen, Guangdong, China) are listed in Table 1. Figure 1 shows the schematic diagram of the laser precision machining system. The beam expander can adjust the divergence angle of the laser to obtain a smaller spot on sample surface. Then using an aperture to improve the spot shape of the laser beam. Finally, the laser beam enters into the galvo scanner, which can control the laser light to move along the predetermined scanning path. The sample was fixed on a 4-axis Computer Numerical Control (CNC) platform (XYZ linear and C axis rotary). Furthermore, a Charge Coupled Device (CCD) camera was used to observe the machining process in real-time and adjust the tool.

Table 1. Parameters of UV nanosecond laser.

\begin{tabular}{cc}
\hline Input Laser Parameters & Values \\
\hline Pulse Width & $10 \mathrm{~ns}$ \\
Wavelength & $355 \mathrm{~nm}$ \\
Pulse Repetition Rate & $40-150 \mathrm{kHz}$ \\
Focal Spot Diameter & $20 \mu \mathrm{m}$ \\
Average Power & $<12 \mathrm{~W}$ \\
Focus Point Diameter & $20 \mu \mathrm{m}$ \\
Divergence Angle & $1.2 \mathrm{mrad}$ \\
\hline
\end{tabular}

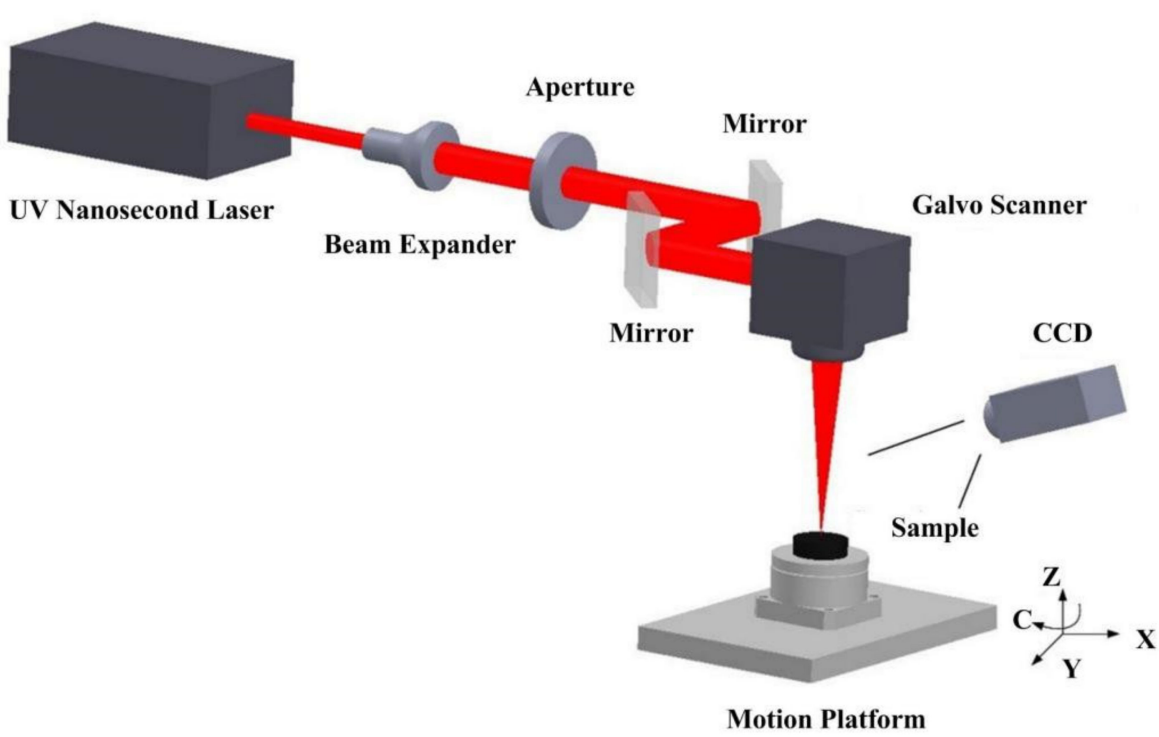

Figure 1. Schematic diagram of laser precision machining system.

To ensure the cutting efficiency, the experiment fixed the pulse repetition rate at $50 \mathrm{kHz}$, at which this laser average power is maximum. We applied a two-step machining method 
combining roughing machining and finishing machining to realize the high precision of the skiving cutter.

During laser roughing machining process, the laser beam transmission direction was vertical to the horizontal plane. During laser finishing machining process, the laser beam was still vertical to the horizontal plane. Between the roughing machining process and the finishing machining process, the PCD workpiece was not rotated or moved, the laser beam was not rotated as well. Therefore, the relative orientation of the reference system determined by the laser beam transmission direction and the reference system determined by the static PCD workpiece was not changed between the roughing machining process and finishing machining process. As is shown in Figures 2 and 3, in laser roughing machining process, laser beam energy was mainly used to etch the PCD material under the focus point of the laser beam. While in the laser finishing machining process, the axial trajectory of the laser beam is basically consistent with the contour the machined outer edge of the gear. In addition, the small outer part of laser beam was mainly used to etch the PCD material. In order to picture the process of laser beam etching the PCD material, the process of laser etching PCD underneath the laser spot during laser roughing and finishing machining process is named orthogonal exposure and tangential exposure in Figures 2 and 3 , respectively.

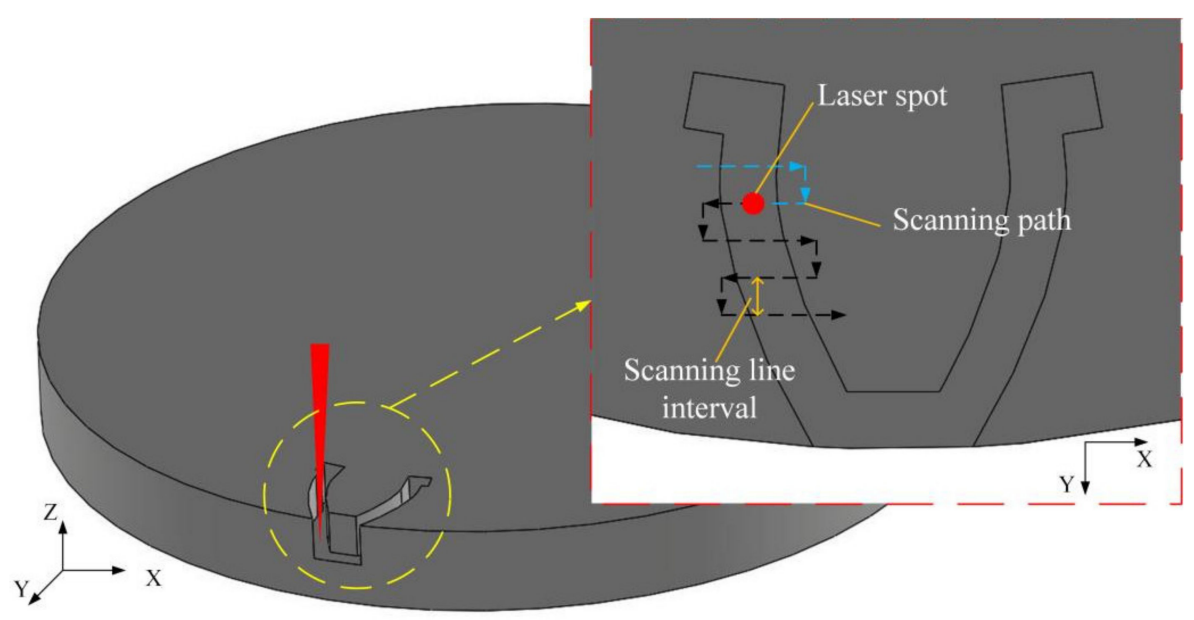

Figure 2. Schematic of laser roughing machining PCD skiving cutter.

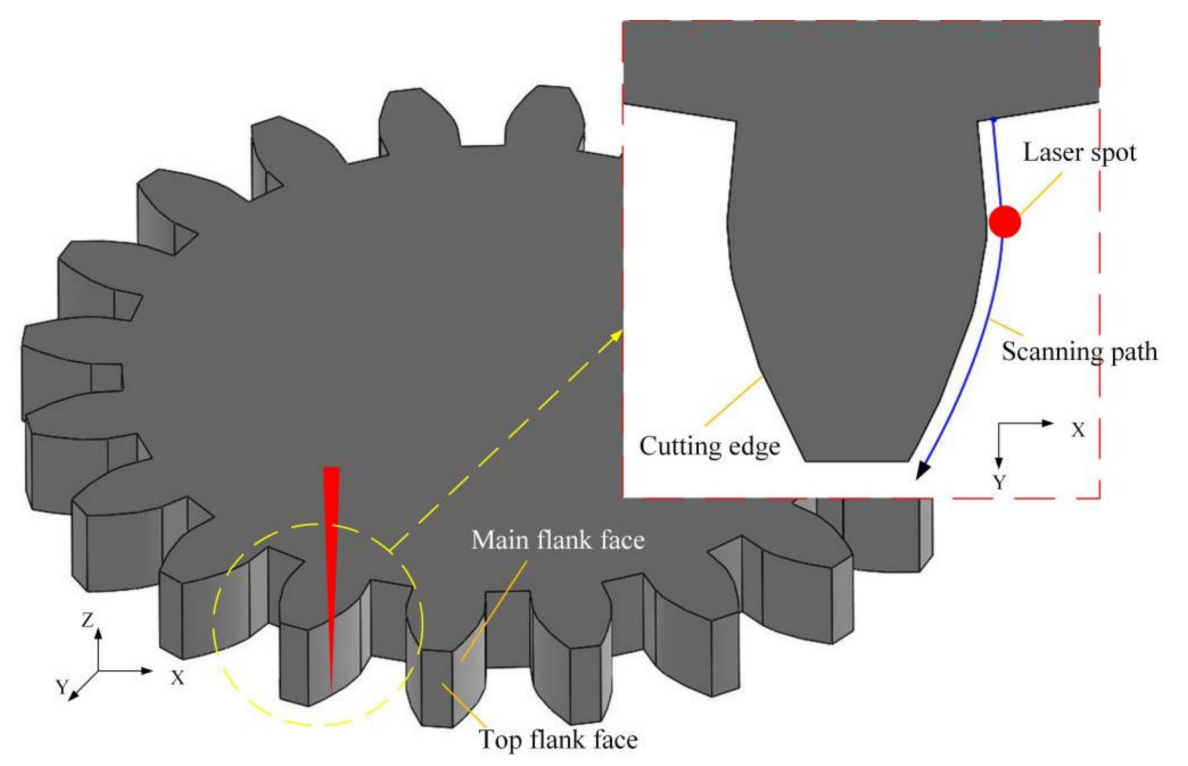

Figure 3. Schematic of laser finishing machining PCD skiving cutter after roughing machining. 
The roughing machining adopted orthogonally irradiation that the direction of the laser beam is perpendicular to the processed surface. Orthogonally irradiation can remove a large amount of material quickly. Meanwhile, the laser beam scanned along the tool contour in an $\mathrm{S}$ shape in the horizontal direction (xy plane) to ensure the basic contour shape of the cutting tool, as illustrated in Figure 2. Moreover, an additional experiment was applied to study the effect of processing parameters on the cutting contour accuracy in the roughing machining. It aims to find a superior parameter combination to minimize the minimum grinding allowance of finishing machining. The finishing machining performed tangentially irradiation that the laser beam is parallel to the processed surface. Moreover, the laser beam scanned rapidly with a tool contour path along the cutting edge, as described in Figure 3. Tangentially machining can polish the flank face and further repair the shape of cutting edge. Therefore, it is feasible to create an excellent PCD skiving cutter.

\section{Results}

\subsection{Simulation Analysis of Diamond under Different Lasers}

The absorptivity of the diamond material to the laser is affected by many factors. The ultraviolet spectrophotometer was adopted to measure the absorption rate of diamond in the laser beam of different wavelength bands. As shown in Figure 4, diamond material has a different laser absorptivity for different wavelength bands. From infrared wavelength to ultraviolet wavelength, the wavelength is shorter and the absorptivity of diamond for the laser is higher. Furtherly, different absorptivity can cause different processing mechanisms of a laser to the diamond. At the same time, the laser with different pulse width also has different effects on the removal of material. Therefore, it is critically important to comprehend the effects of diverse lasers on the diamond. Considering the types of lasers in the field of micromachining, this study mainly concerns the infrared band femtosecond laser (FSL) with a wavelength of $1064 \mathrm{~nm}$, the green band picosecond laser (PSL) with a wavelength of $532 \mathrm{~nm}$ and the UV nanosecond laser (NSL) with a wavelength of $355 \mathrm{~nm}$.

The main heat transfer is due to the heat conduction when the laser irradiates on the diamond. In the case of heat conduction, Fourier's law of heat transfer can describe the temperature distribution of material in space and its change over time. The corresponding 2-D model was established with the solid heat transfer module in the commercial software of Comsol Multiphysics (5.4, Comsol Inc., Stockholm, Sweden). To simplify the model, some assumptions are indispensable. The material's removal process mainly considers the thermal effect and ignores the chemical effect. In laser micromachining, plasma generation do not affect the heat absorption. The material is vaporizing and removed at once when the temperature of material reaches the vaporization point. Then, a Gaussian heat source model was established to simulate the laser source.

When laser irradiates on the material, the material cannot absorb the laser energy completely. Most of the incident laser will be absorbed, some will be reflected by the surface, some will be lost when laser pass through the material and some will be scattered by the surface. According to energy conservation, the relationship between material absorption and propagation of laser beam is:

$$
A+R+T+S=1
$$

In this equation, $A$ is the absorption rate of material to the laser, $R$ is the reflectivity of material to the laser, $T$ is light transmittance of material, $S$ is the scattering coefficient of material.

For diamond, the $T$ and $S$ can be neglected. The Equation (1) can evolve to the following equation:

$$
A+R \approx 1
$$

The Gaussian flux was applied on the surface of the model, and the surface emissivity was set. The different absorption coefficients were also set according to the absorption rate of different lasers by diamond. The parameters of different lasers are listed in Table 2. After 
calculation, the simulation results illustrate the material removal and the temperature field distribution as shown in Figure 5. The pit morphology and temperature field distribution after the three kinds of laser are nearly v-shaped, which determined by the temperature distribution of the Gaussian laser (the temperature decreases gradually from the center to the outside). It also found that the pit morphology of NSL is more positive and deeper than FSL and PSL.

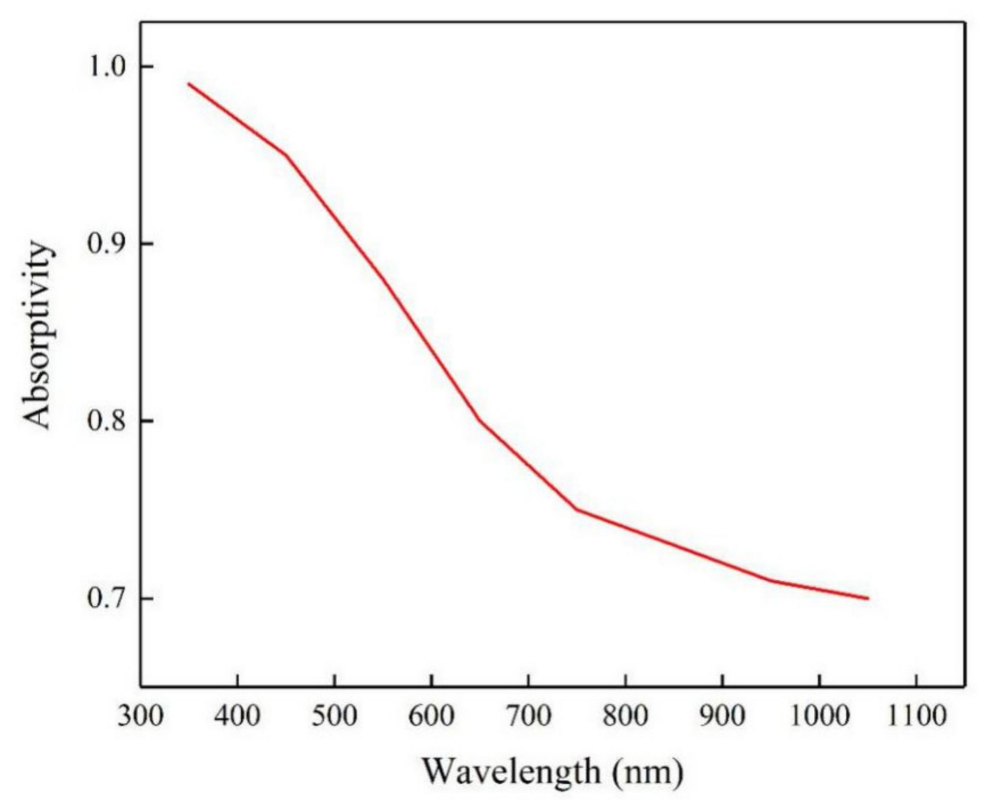

Figure 4. Absorption rate of diamond to the laser with different wavelength.

Table 2. Parameters of the FSL, PSL, NSL used in the simulation.

\begin{tabular}{cccc}
\hline & FSL & PSL & NSL \\
\hline Pulse Width & $120 \mathrm{fs}$ & $10 \mathrm{ps}$ & $10 \mathrm{~ns}$ \\
Wavelength & $1064 \mathrm{~nm}$ & $532 \mathrm{~nm}$ & $355 \mathrm{~nm}$ \\
Pulse Repetition Rate & $200 \mathrm{kHz}$ & $1 \mathrm{MHz}$ & $50 \mathrm{kHz}$ \\
Pulse Energy & $100 \mu \mathrm{J}$ & $100 \mu \mathrm{J}$ & $200 \mu \mathrm{J}$ \\
\hline
\end{tabular}

The diamond will transform into graphite while the temperature reaches $1233 \mathrm{~K}$ and graphite will be removed by gasification at $4827 \mathrm{~K}$ [15]. Thus, it can consider that the material with a temperature between $1233 \mathrm{~K}$ and $4827 \mathrm{~K}$ is the graphite layer. A 2D intercept line was used to measure the depth from the pit to the bottom of the model. The depth can represent the phase transition degree. In Figure 6, the degree of graphitization of NSL is similar to the ultrafast laser, and the graphite layer is thinner than FSL and PSL. That is because the diamond has an extremely high absorption of laser energy with an ultraviolet band, which results in the photon energy being strong enough to break directly the molecular bonds of material to etch the material through photochemical mechanism instead of ablation which occurs when infrared band or green band laser radiate on diamond [16-21]. Thus, UV nanosecond laser has superior results. This simulation substantiates that it mainly depends on laser wavelength rather than the pulse width. The wavelength of the laser governs the processing mechanism and phase transition of the diamond. Furthermore, nanosecond has higher efficiency than femtosecond and picosecond laser. Therefore, UV nanosecond is more positive to fabricate the PCD skiving cutter. 


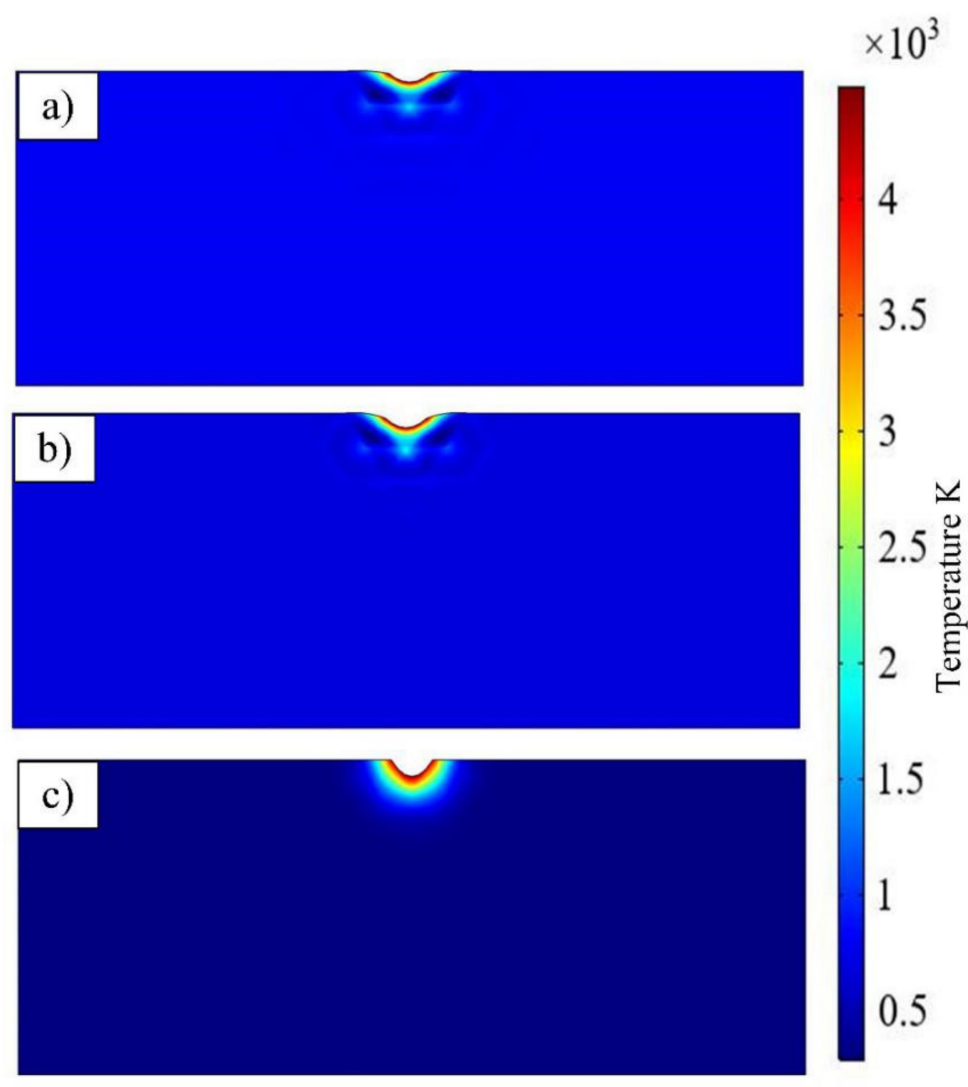

Figure 5. Comparison of the ablation and temperature distribution after one pulse of (a) FSL, (b) PSL and (c) NSL irradiation.

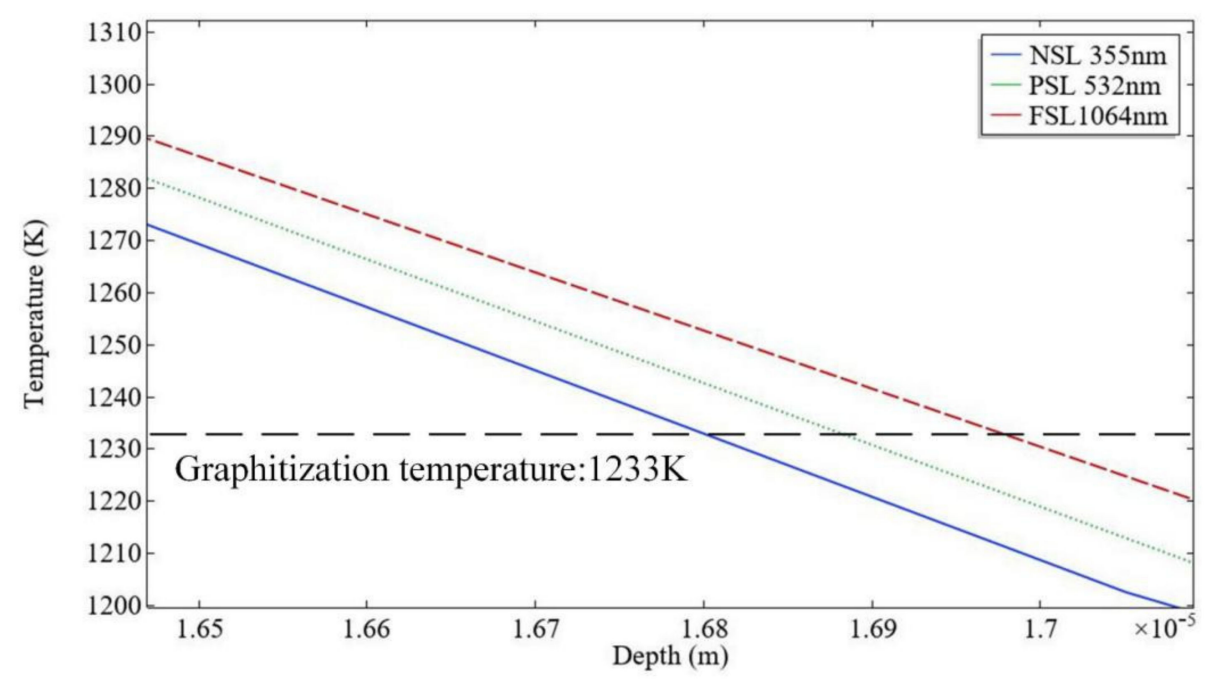

Figure 6. Comparison of graphitization depth under FSL, PSL and NSL irradiation.

The simulation is carried out in 2D symmetry model, which can lead to quantitative assessment of laser exposure induced graphitization. The simulate plate is selected on the symmetry plane of the laser load of the PCD workpiece.

\subsection{Influence of Laser Processing Parameters on Contour Accuracy}

The contour accuracy of the cutting tool has a crucial impact on the performance of the cutting tool, and it is one of the significant standards for evaluating the quality of laser cutting. Here, $R_{\mathrm{tp}}$ is defined as the contour accuracy of the cutting edge, which 
is numerically equal to the maximum peak-valley deviation between the actual contour and theoretical contour, shown in Figure 7. The laser scanning line interval, defocusing amount and scanning speed are the main parameters that affect the $R_{\mathrm{t}}$ as the laser power is constant. Hence, this section investigated the influence of laser scanning line interval, defocusing amount and scanning speed on the $R_{\mathrm{t}}$ according to the processing method shown in Figure 2, and detected the processing results through the scanning electron microscope.

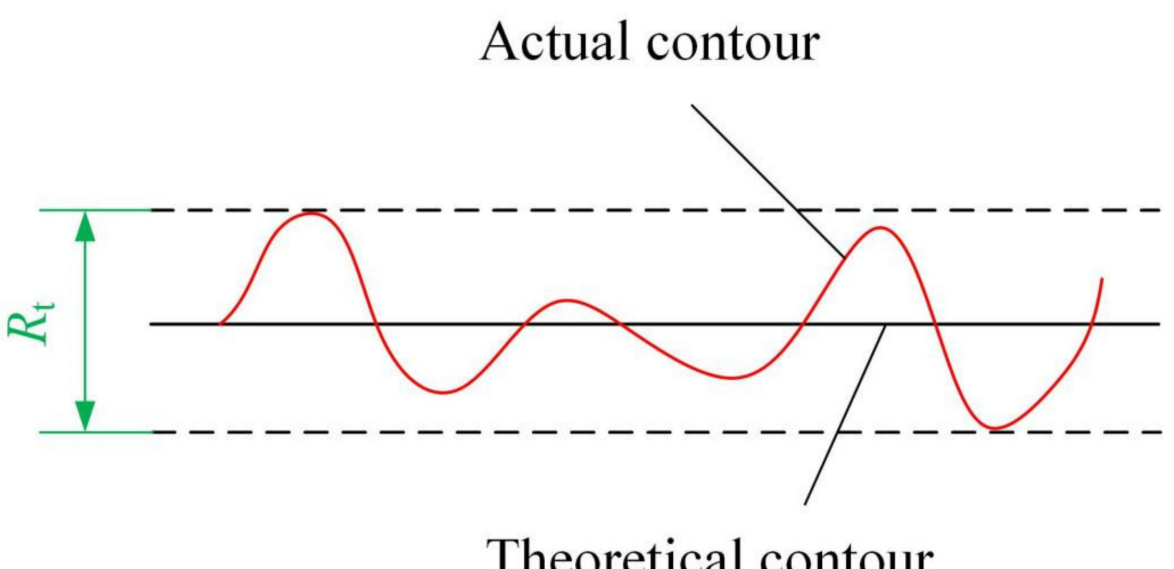

Figure 7. Schematic of $R_{\mathrm{t}}$ measurement.

The effect of laser scanning line interval on $R_{\mathrm{t}}$ at a laser power of $10 \mathrm{~W}$, scanning speed of $500 \mathrm{~mm} / \mathrm{s}$ and defocusing amount of 0 , is shown in Figure 8. As the line interval increases, the $R_{\mathrm{t}}$ decreases gradually at first and then increases. The $R_{\mathrm{t}}$ has a minimum value when the line interval is $3 \mu \mathrm{m}$ in Figure $9 \mathrm{~b}$, the defect is very small. However, when decreasing the line interval, the overlap rate of the laser spot increases. The energy density raises accordingly, resulting in excessive etching at the cutting edge. In Figure 9a, there are a few defects at the edge as the line interval is $1 \mu \mathrm{m}$. Similarly, the overlap rate is undersize when the line interval is too large. The energy density reduces accordingly, in result incomplete removal of the material at the cutting edge, which causes the raising of the $R_{\mathrm{t}}$ value further, such as the defects shown in Figure 9c.

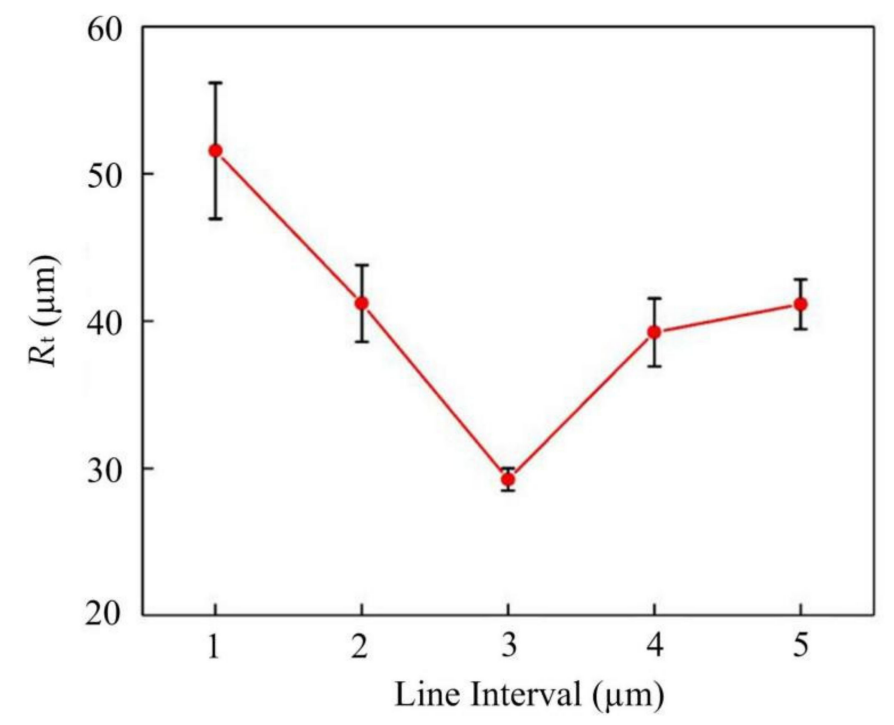

Figure 8. The effect of line interval on the $R_{\mathrm{t}}$. 

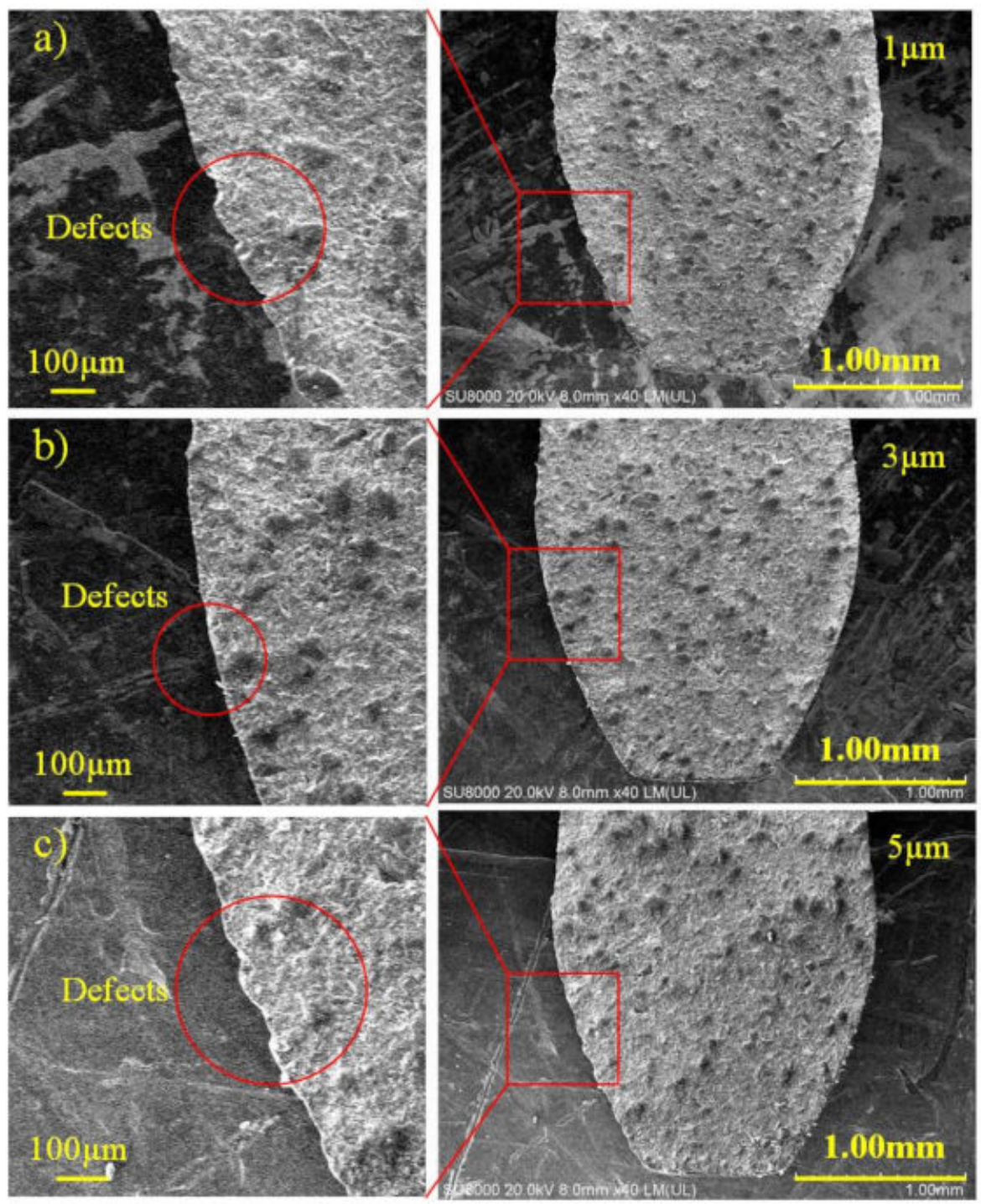

Figure 9. The SEM images of cutting edge of PCD skiving cutter at different line interval: (a) $1 \mu \mathrm{m}$, (b) $3 \mu \mathrm{m}$, (c) $5 \mu \mathrm{m}$.

The SEM image of the cutting edge at a laser power of $10 \mathrm{~W}$, a line interval of $1 \mu \mathrm{m}$, a scanning speed of $500 \mathrm{~mm} / \mathrm{s}$ and a negative defocusing amount of $-300 \mu \mathrm{m}$ is demonstrated in Figure 10a. The defects are not negligible. The reason for the obvious defects is that the focus point is far from the cutting edge, the energy density irradiated on the edge is low so that the material cannot remove uniformly. When decreasing the defocusing amount, the average power increases with a better result. It can be seen in Figure 10b, the defects are reduced obviously. However, when further moving the focus point up, the accuracy becomes worse in Figure 10c. This change largely results from the fact that the energy density interacted on the edge heighten, which results in excessive etching. Further, the experiment was also applied under the positive defocus condition. The effect of the defocusing amount is exhibited in Figure 11. The result reveals an analogic influence. The $R_{\mathrm{t}}$ value decreases first and then increases, regardless of whether the defocusing amount is positive or negative. In addition, the $R_{\mathrm{t}}$ value is smallest at a positive defocusing amount of $100 \mu \mathrm{m}$. This result reveals an appropriate defocusing amount can reduce the laser energy density on the cutting edge and achieve a favorable processing result. 

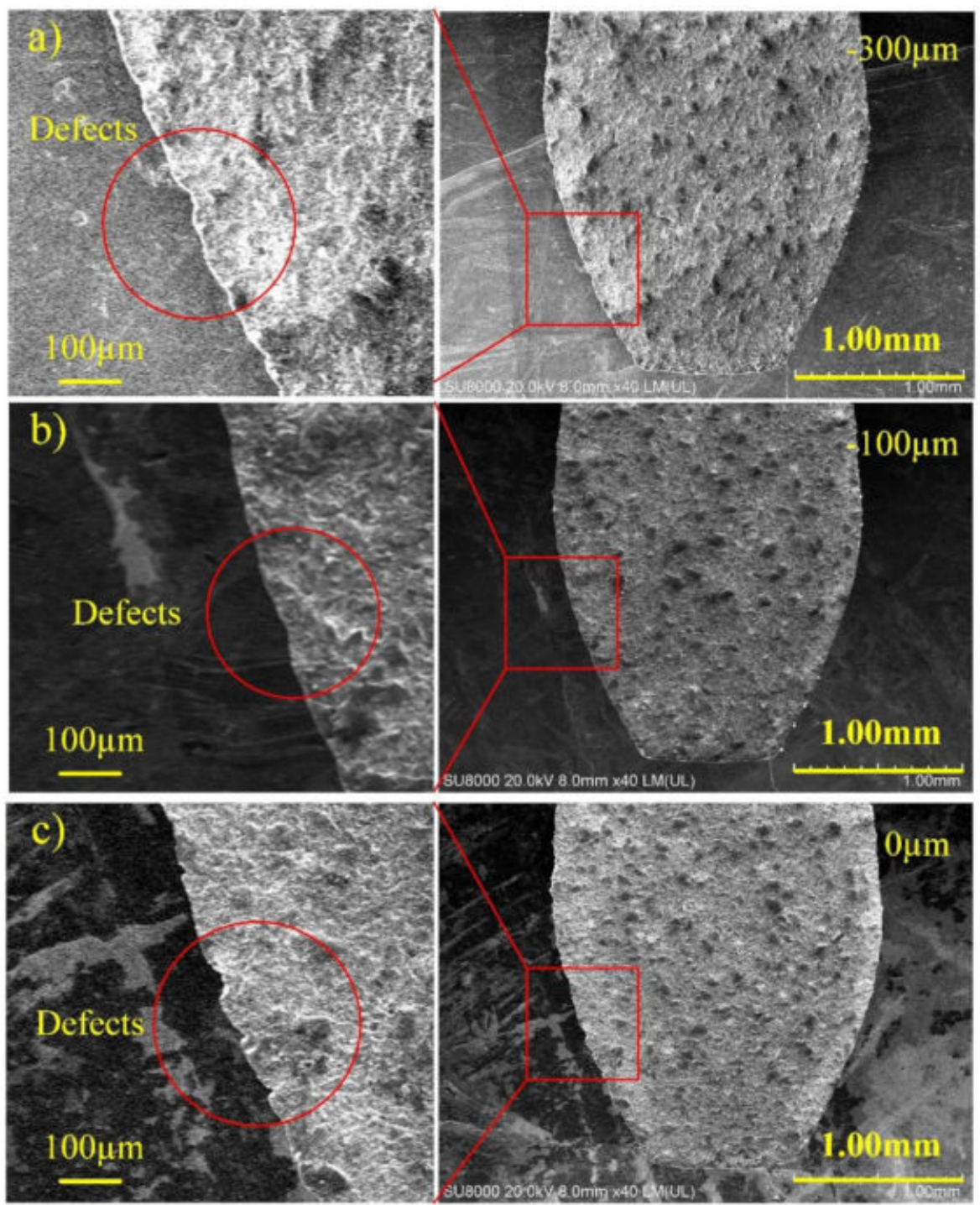

Figure 10. The SEM images of cutting edge of PCD skiving cutter at different defocusing amount: (a) $-300 \mu \mathrm{m},(\mathbf{b})-100 \mu \mathrm{m},(\mathbf{c}) 0 \mu \mathrm{m}$.

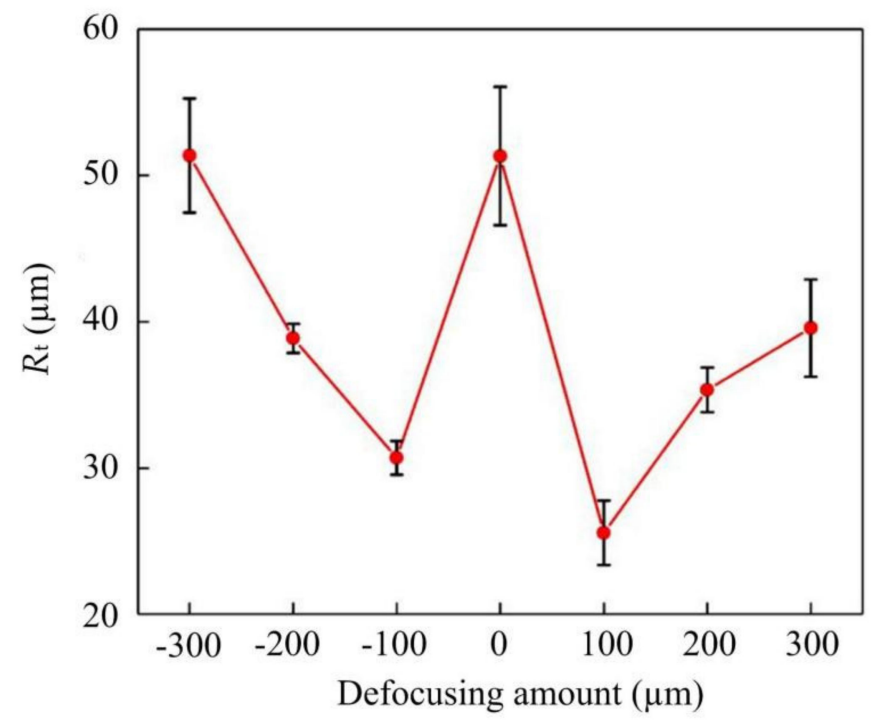

Figure 11. The effect of defocusing amount on the $R_{\mathrm{t}}$. 
The SEM images of the cutting edge under different scanning speed are shown in Figure 12. The effect of scanning speed on $R_{\mathrm{t}}$ at a laser power of $10 \mathrm{~W}$, a line interval of $1 \mu \mathrm{m}$ and a defocusing amount of 0 , is manifested in Figure 13. The results indicate that $R_{\mathrm{t}}$ gradually decreases first and then increases with the increase of scanning speed. The reason is analogic that the spot overlap rate raises with the decrease of scanning speed. It causes a great energy density at the cutting edge, resulting in excessive etching and poor accuracy. However, the energy at the cutting edge is insufficient when the scanning speed is too high, so the $R_{\mathrm{t}}$ increases accordingly.
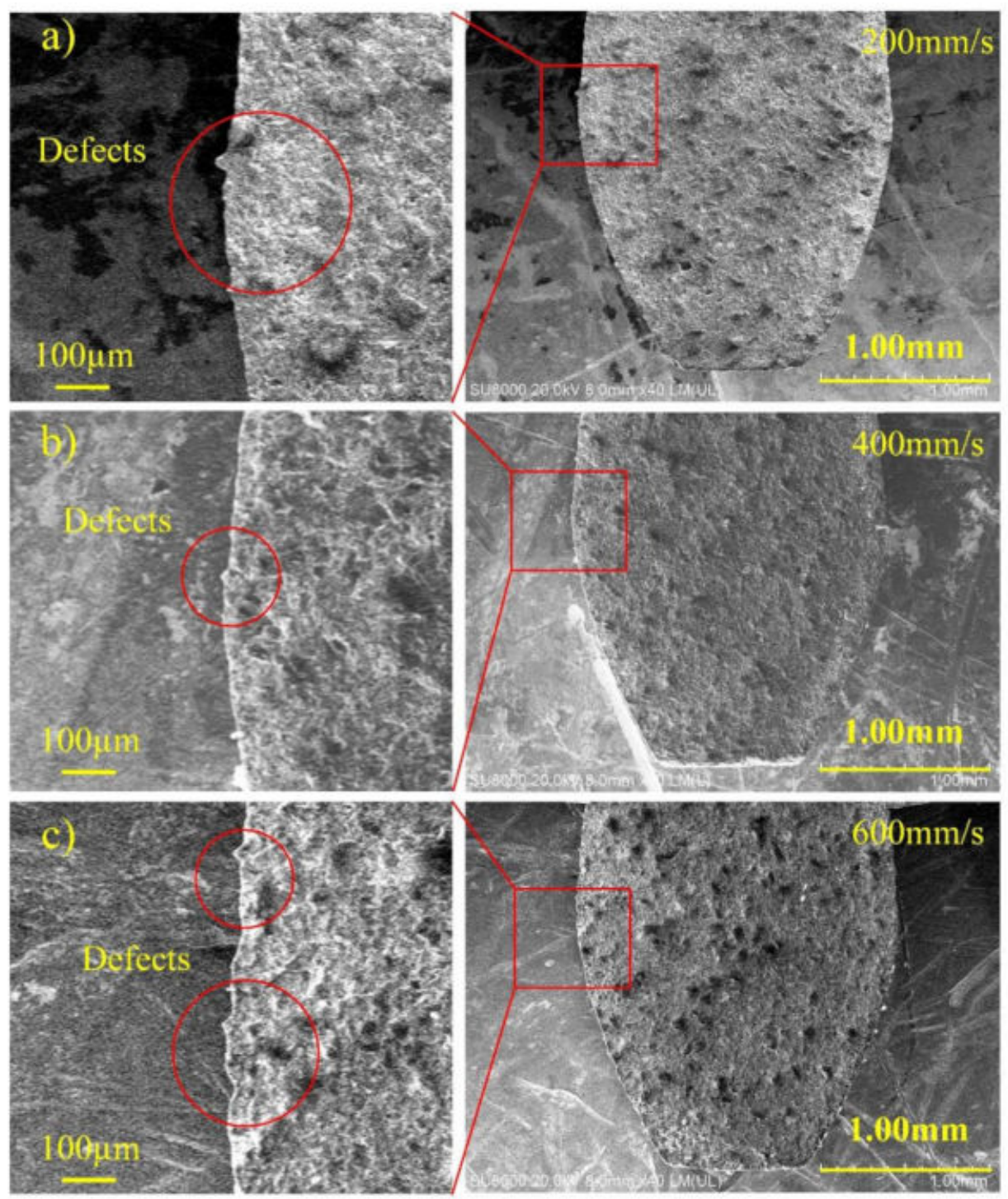

Figure 12. The SEM images of cutting edge of PCD skiving cutter at different scanning speed: (a) $200 \mathrm{~mm} / \mathrm{s}$, (b) $400 \mathrm{~mm} / \mathrm{s}$, (c) $600 \mathrm{~mm} / \mathrm{s}$.

The above-mentioned research presents that the processing parameters govern the contour accuracy of the cutting edge. A positive cutting edge can be obtained by adjusting different processing parameters to regulate the energy density for acting on the cutting edge. 
(a)

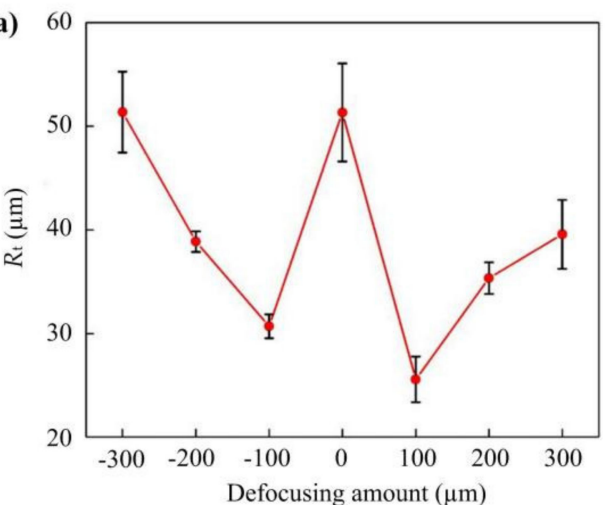

(b)

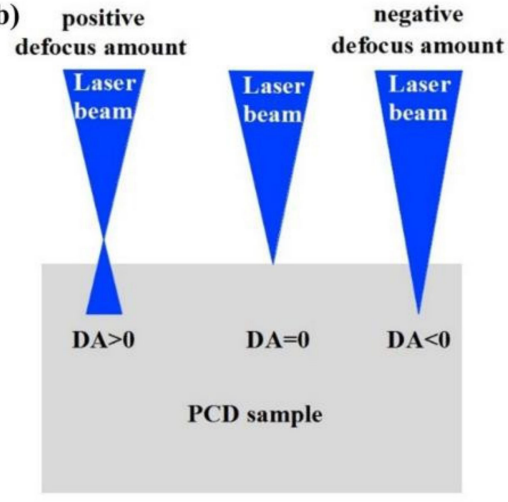

Figure 13. (a) The effect of scanning speed on the $R_{\mathrm{t}}$ and (b) the definition of defocus amount.

\subsection{Finishing Processing}

We can use the above-mentioned parameter combination to make the PCD blank into rough shape. Furtherly, finishing the tool by the finishing machining method described in Figure 3. The PCD skiving cutter processed is shown in Figure 14. The single tooth cutting edge is described in Figure 15. It indicates that the cutting edge is flat without any cracking defects. Moreover, the $R_{\mathrm{t}}$ value reaches $5.6 \mu \mathrm{m}$ after finishing processing.
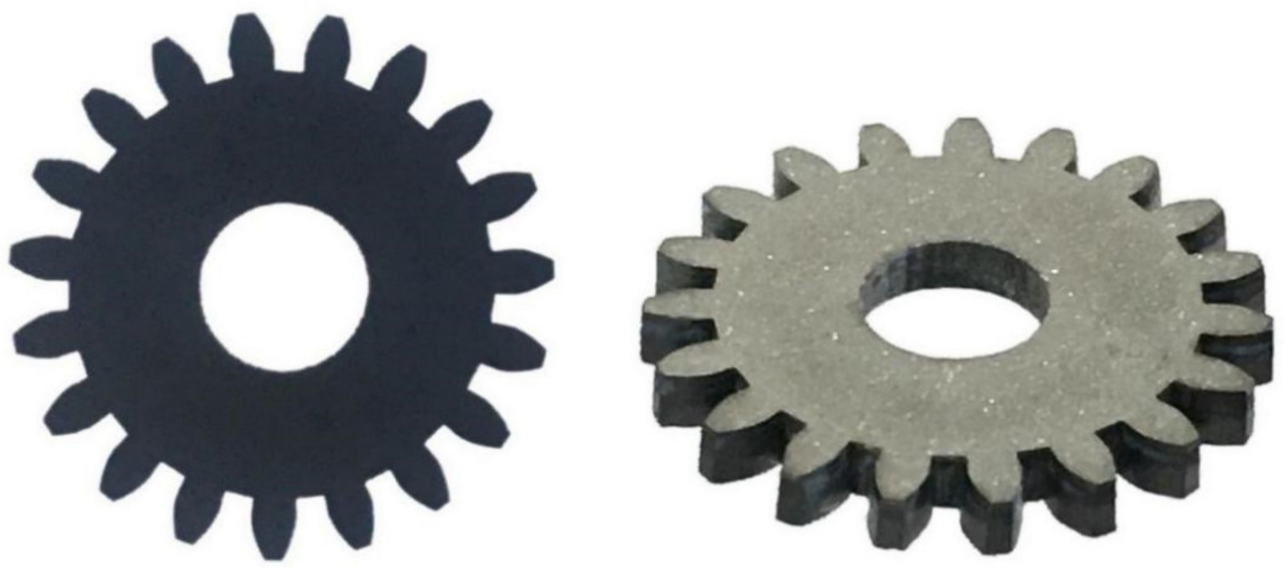

Figure 14. The material object images of PCD skiving cutter.
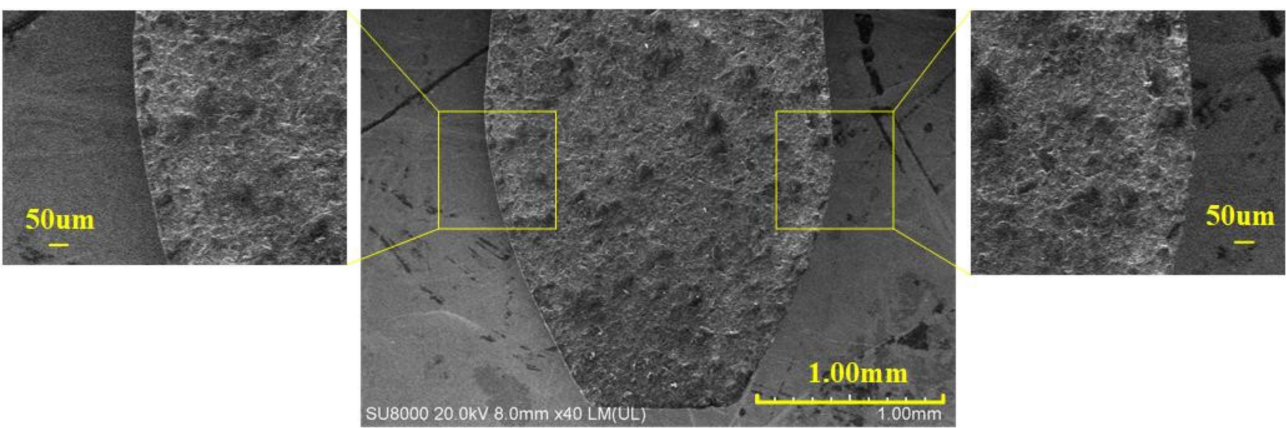

Figure 15. The SEM image of cutting edge of PCD skiving cutter.

\subsection{Raman Spectroscopy Analysis}

The Raman spectroscopy was used to investigate the effect of different cutting methods on the phase transition of the diamond and characterized the flank face of the PCD skiving cutter to extrapolate the influence of laser cutting on cutting tool. Figure 16 gives the Raman spectroscopy in a few conditions. For unprocessed PCD blank (black curve), there 
is only a peak at $1335 \mathrm{~cm}^{-1}$, which represents the $\mathrm{sp}^{3}$ (diamond-like) hybrid structure. After orthogonally irradiation (red curve), there exists a peak in D-band at $1350 \mathrm{~cm}^{-1}$ and G-band at $1590 \mathrm{~cm}^{-1}$. It indicates a mixture of carbon phase with disorder and $\mathrm{sp}^{2}$ (graphite-like) hybrid structure. In contrast, the spectrum of tangentially irradiated (blue curve) only has the diamond phase. The reason for this difference is that the laser is in tangential contact with the material for the tangentially irradiated, the energy density absorbed by the material is limited. It is similar to the laser polishing, and the subsequent UV laser can remove the graphite component caused by the previous laser. This research provides evidence for the practicability of the skiving cutter processing technology.

For further proving this research, a Raman test of the main flank face and top flank face generated by a two-step machining demonstrated as before is significant. As expected, the Raman spectroscopy (green and purple curve) exhibits only an obvious peak at $1335 \mathrm{~cm}^{-1}$ for both two faces, indicating a strong $\mathrm{sp}^{3}$ bonds, respectively. Therefore, the two-step fabrication process is feasible to obtain an PCD skiving cutter without phase transition.

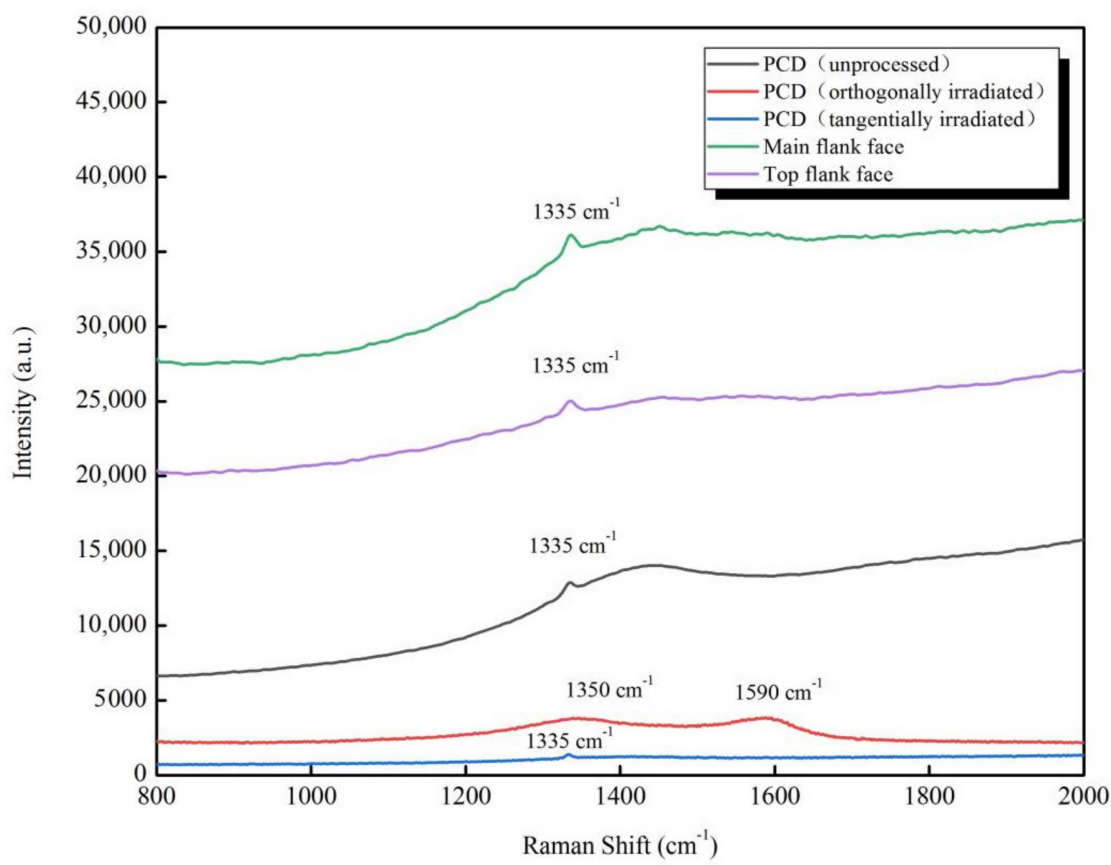

Figure 16. Raman spectroscopy on different conditions.

\section{Conclusions}

In this study, a two-step laser machining process combining roughing machining and finishing machining was proposed and performed with UV nanosecond laser. During the roughing machining, the orthogonally irradiation was adopted to make a rough shape of the skiving cutter. Subsequently, tangentially irradiation was used in finishing machining to process a high-accuracy cutting edge. The simulation results indicate UV nanosecond laser can acquire a more positive cutting result with less graphitizing, flatter morphology. In experiments, $R_{\mathrm{t}}$ value decreases first and then increases as the increase of the line interval, scanning speed and defocusing amount (no matter positive or negative defocus). A minimum of $R_{\mathrm{t}}$ can be received at a line interval of $3 \mu \mathrm{m}$, a positive defocusing amount of $100 \mu \mathrm{m}$ and a scanning speed of $400 \mathrm{~mm} / \mathrm{s}$. Through the Raman spectrum of the flank face of the PCD skiving cutter, the cutting face on a diamond has no graphite phase transition with the UV nanosecond laser machining. In addition, after the two-step machining, a superior PCD skiving cutter with an $R_{\mathrm{t}}$ of $5.6 \mu \mathrm{m}$ was obtained in this study.

Author Contributions: Conceptualization, J.C. and X.M.; methodology, J.C.; software, X.F. and X.D.; validation, J.C., X.M., K.X., Z.F., Z.S. and W.W.; formal analysis, J.C. and X.D.; investigation, J.C., X.F. and X.D.; resources, J.C., X.M., K.X., Z.F., Z.S. and W.W.; data curation, J.C., X.F. and X.D.; writing- 
original draft preparation, X.F. and J.C.; writing—review and editing, J.C., X.D. and X.F.; visualization, X.F.; supervision, J.C. and X.M.; project administration, J.C. and X.M.; funding acquisition, J.C. and X.M. All authors have read and agreed to the published version of the manuscript.

Funding: This research was funded by National Key Research and Development Program of China (2020YFA0709702), Shaanxi Provincial Key Research and Development Program (2021ZDLGY10-02), Key-Area Research and Development Program of Guangdong Province (2018B090905003), Science and Technology Innovation Commission Shenzhen (JCYJ20180306170821261).

Institutional Review Board Statement: Not applicable.

Informed Consent Statement: Not applicable.

Data Availability Statement: The data presented in this study are available on request from the corresponding author.

Conflicts of Interest: The authors declare no conflict of interest.

\section{References}

1. Arsecularatne, J.; Zhang, L.; Montross, C. Wear and tool life of tungsten carbide, PCBN and PCD cutting tools. Int. J. Mach. Tools Manuf. 2006, 46, 482-491. [CrossRef]

2. Suzuki, H.; Moriwaki, T.; Yamamoto, Y.; Goto, Y. Precision Cutting of Aspherical Ceramic Molds with Micro PCD Milling Tool. CIRP Ann. 2007, 56, 131-134. [CrossRef]

3. Brinksmeier, E.; Mutlugünes, Y.; Klocke, F.; Aurich, J.C.; Shore, P.; Ohmori, H. Ultra-precision grinding. CIRP Ann. 2010, 59, 652-671. [CrossRef]

4. Dou, J.; Cui, J.; Fang, X.; Dong, X.; Ullah, N.; Xu, M. Theoretical and Experimental Study on Machining Rectangular Microgroove of Diamond by Femtosecond Laser. Integr. Ferroelectr. 2020, 208, 104-116. [CrossRef]

5. Dou, J.; Sun, Y.; Xu, M.; Cui, J.; Mei, X.; Wang, W.; Wang, X. Process research on micro-machining diamond microgroove by femtosecond laser. Integr. Ferroelectr. 2019, 198, 9-19. [CrossRef]

6. Tso, P.-L.; Liu, Y.-G. Study on PCD machining. Int. J. Mach. Tools Manuf. 2002, 42, 331-334. [CrossRef]

7. Jia, Y.; Li, J.G.; Lu, X.J. Study on EDM Machining Technics of Polycrystalline Diamond Cutting Tool and PCD Cutting Tool's Life. Adv. Mater. Res. 2011, 268-270, 309-315. [CrossRef]

8. Sun, Y.; Dou, J.; Xu, M.; Cui, J.; Mei, X.; Wang, W.; Gao, M. Research on the mechanism of micromachining of CVD diamond by femtosecond laser. Ferroelectrics 2019, 549, 266-275. [CrossRef]

9. Dold, C.; Henerichs, M.; Bochmann, L.; Wegener, K. Comparison of Ground and Laser Machined Polycrystalline Diamond (PCD) Tools in Cutting Carbon Fiber Reinforced Plastics (CFRP) for Aircraft Structures. Procedia CIRP 2012, 1, 178-183. [CrossRef]

10. Butler-Smith, P.; Axinte, D.; Pacella, M.; Fay, M. Micro/nanometric investigations of the effects of laser ablation in the generation of micro-tools from solid CVD diamond structures. J. Mater. Process. Technol. 2013, 213, 194-200. [CrossRef]

11. Harrison, P.M.; Henry, M.; Brownell, M. Laser processing of polycrystalline diamond, tungsten carbide, and a related composite material. J. Laser Appl. 2006, 18, 117. [CrossRef]

12. Everson, C.; Molian, P.; Everson, C.; Molian, P. Fabrication of polycrystalline diamond microtool using a Q-switched Nd:YAG laser. Int. J. Adv. Manuf. Technol. 2009, 45, 521-530. [CrossRef]

13. Konrad, W.; Claus, D.; Marcel, H.; Christain, W. Laser Prepared Cutting Tools. Phys. Procedia 2012, 39, 240-248. [CrossRef]

14. Dold, C.; Henerichs, M.; Gilgen, P.; Wegener, K. Laser Processing of Coarse Grain Polycrystalline Diamond (PCD) Cutting Tool Inserts using Picosecond Laser Pulses. Phys. Procedia 2013, 41, 610-616. [CrossRef]

15. Wang, S.; Sun, B.Y.; Wang, Y.C.; Zhang, H.T. Study on the graphitization temperature of polycrystalline diamond. Superhard Mater. Eng. 2005, 17, 32-35. (In Chinese)

16. Xiang, S.; Xiang, X.; Feng, C. Analysis on action characteristic of laser upon energetic materials. Laser Infrared 2002, 32, 233-236. (In Chinese)

17. Yuan, H.; Li, J.; Liu, H.; Li, Z.; Xu, K.; Sun, Z.; Sun, X.; Chen, G. Single crystal diamond trenched by UV pulsed laser. Surf. Technol. 2018, 47, 24-28. (In Chinese)

18. Stuart, B.C.; Feit, M.D.; Herman, S.; Rubenchik, A.M.; Shore, B.W.; Perry, M.D. Optical ablation by high-power short-pulse lasers. J. Opt. Soc. Am. B 1996, 13, 459-468. [CrossRef]

19. Lenzner, M.; Krüger, J.; Sartania, S.; Cheng, Z.; Spielmann, C.; Mourou, G.; Kautek, W.; Krausz, F. Femtosecond Optical Breakdown in Dielectrics. Phys. Rev. Lett. 1998, 80, 4076-4079. [CrossRef]

20. Stuart, B.C.; Feit, M.D.; Herman, S.; Rubenchik, A.M.; Shore, B.W.; Perry, M.D. Nanosecond-to-femtosecond laser-induced breakdown in dielectrics. Phys. Rev. B 1996, 53, 1749. [CrossRef]

21. Li, L.S.; Jiang, L.; Wang, S.M. Microscopic energy transport through photon-electron-phonon interactions during ultrashort laser ablation of wide bandgap materials Part II: Phase change. Chin. J. Lasers 2009, 36, 1029-1036. [CrossRef] 